\title{
Virulence factors of Shiga toxin-producing Escherichia coli and the risk of developing haemolytic uraemic syndrome in Norway, 1992-2013
}

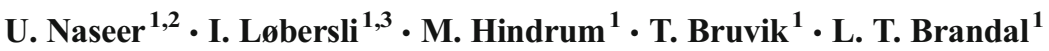

Received: 14 February 2017 / Accepted: 22 March 2017 /Published online: 8 April 2017

(C) The Author(s) 2017. This article is published with open access at Springerlink.com

\begin{abstract}
Shiga toxin-producing Escherichia coli (STEC) may cause haemolytic uraemic syndrome (HUS). Age $\leq 5$ years and presence of $s t x 2 a$ and eae are risk factors for the development of HUS. In this study, we investigated STEC isolates for the presence of adhesins, toxins and molecular risk assessment (MRA) factors to identify virulence genes associated with HUS development. We included nonduplicate isolates from all STEC infections $(n=340$, HUS $=32$ ) reported to the Norwegian National Reference Laboratory (NRL) for Enteropathogenic Bacteria from 1992 to 2013. The most common STEC were $\mathrm{O} 157: \mathrm{H}^{7} / \mathrm{H}^{-}$(34\%) and $\mathrm{O} 103: \mathrm{H} 2$ (14\%). We retrospectively screened the isolates by three multiplex polymerase chain reactions (PCRs) for adhesins $(n=11)$, toxins $(n=5)$ and MRA $(n=15)$. We calculated odds ratios (ORs) and adjusted odds ratios (aORs) for associations with HUS development. On average, isolates were positive for 15 virulence genes (range: 1-24); two toxins (range: $0-4$ ), five adhesins (range: $0-8$ ) and eight MRA genes (range: $0-13$ ). The gene combinations were clustered within
\end{abstract}

Electronic supplementary material The online version of this article (doi:10.1007/s10096-017-2974-z) contains supplementary material, which is available to authorized users.

U. Naseer

mohammed.umaer.naseer@ fhi.no

1 Domain for Environmental Health and Infectious Disease Control, Norwegian Institute of Public Health, P.O. Box 4404 Nydalen, 0403 Oslo, Norway

2 European Programme for Public Health Microbiology Training (EUPHEM), European Centre for Disease Prevention and Control (ECDC), Stockholm, Sweden

3 Nextera AS, Oslo, Norway serotypes. Isolates from HUS cases were positive for eae and IpfA $A_{\mathrm{O} 26}$, and negative for saa, eibG, astA, cnf, subA and pic. We identified 11 virulence genes with a significant association to HUS development. Multivariable analyses adjusted for age group and Shiga toxin identified nleH1-2 [aOR 8.4, 95\% confidence interval (CI); 2.18-32.3] as an independent risk factor for the development of HUS from an STEC infection. This study demonstrated that the non-LEE effector protein nleH1-2 may be an important predictor for elevated risk of developing HUS from STEC infections. We recommend the NRL for Enteropathogenic Bacteria to consider including nleH1-2 screening as part of routine STEC surveillance.

\section{Introduction}

Shiga toxin-producing Escherichia coli (STEC) is a zoonotic food- and waterborne pathogen of a serious public health concern because of its propensity to cause outbreaks, haemorrhagic colitis and the potentially life-threatening complication haemolytic uraemic syndrome (HUS) [1, 2]. It is estimated that 6-25\% of patients infected with STEC develop HUS, with up to $50 \%$ requiring renal dialysis. In children, this rate is much higher [1]. HUS generally complicates $6-9 \%$ of STEC infections overall and about $15 \%$ of infections in children, with mortality of $2-5 \%$ and up to $30 \%$ developing longterm sequelae $[2,3]$. Currently, there are no available treatments for HUS and prevention strategies are limited.

The production of bacteriophage-encoded Shiga toxin $2 \mathrm{a}$ (Stx2a) by STEC is the primary virulence trait responsible for HUS development, along with the presence of intimin (eae) and young age of the host ( $\leq 5$ years old) [4-6]. However, not all cases of STEC infections harbouring these characteristics develop HUS. The clinical significance of STEC for humans is further determined by the production and interplay of 
additional virulence factors, as well as host factors such as immunocompetence [7, 8].

Typically, STEC strains harbour the genomic island termed the 'locus of enterocyte effacement' (LEE), which encodes genes that facilitate the colonisation process (e.g. eae). The LEE also encodes a series of proteins that induce cytoskeletal changes in the eukaryotic target cell to enhance attachment and effacement of the bacterium [9, 10]. In addition, many virulence factors, such as the plasmid-encoded enterohaemolysin (ehxA), have been shown to be important for the pathogenicity of STEC. A number of candidate pathogenicity islands (PAIs), including OI-122 and OI-71, encode a variable repertoire of non-LEE-encoded effector (nle) proteins which are present in many STEC strains. However, their role in disease development is not yet fully understood $[8,11$, 12].

Recently, we published a comprehensive study spanning 20 years from 1992 to 2012, where we investigated host factors such as age, sex and clinical manifestations, and strain factors such as serotypes, stx types and the presence of eae and ehxA, with the association of developing HUS from STEC infections in Norway [5]. Following in line with the concept of a molecular risk assessment (MRA) [13], the objective of this study was to identify virulence factors important for HUS development, to enable an improved differentiation of HUSassociated STEC from low virulent STEC infections and expand the Norwegian STEC surveillance system.

\section{Methods}

\section{Case definition, strain and data collection}

An STEC infection was defined as the isolation of an STEC from a clinical sample. We retrospectively included all nonduplicate STEC isolates, one isolate per outbreak (unless different virulence gene profiles were detected), submitted to the National Reference Laboratory (NRL) for Enteropathogenic Bacteria from 1992 to 2012 ( $n=334)$. In addition, we included all STEC isolates recovered from HUS patients in Norway in $2013(n=6)$. HUS was defined as acute renal failure within 14 days of an episode of acute diarrhoea with either microangiopathic haemolytic anaemia or thrombocytopaenia. Clinical and epidemiological information of cases corresponding to the selected STEC isolates were retrieved from the Norwegian Surveillance System for Communicable Diseases database.

\section{Serotyping}

All isolates were consecutively serotyped at the NRL on reception using slide agglutination against 43 different $\mathrm{O}$ groups, fliC-PCR for $\mathrm{H}$ groups and $w z x$ - and $w z y$-PCR for
$14 \mathrm{O}$ groups for non-agglutinating isolates, as described previously [5].

\section{Sorbitol-fermenting (SF) E. coli 0157}

Isolates belonging to serogroup $\mathrm{O} 157$ were analysed for sorbitol fermentation by polymerase chain reaction (PCR) as described previously [5].

\section{Virulence genes characterisation}

All isolates were consecutively screened for the presence of genes stxla, $c, d$, stx $2 a-g$, eae and $e h x A$ by PCRs, as described previously [5]. In addition, all isolates were retrospectively screened for five toxin genes (cnf, astA, subA, StcE/ $\left.S t c E_{0103}, c d t B I-I V\right), 11$ adhesin genes (saa, ihaA,

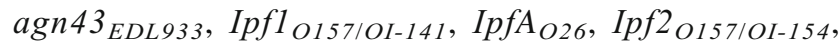
$I p f A_{O 113}$, eibG, toxB, espP, ehaA) and 15 genes previously classified as MRA genes [14-18] (aaiC, fyuA, ent/espL2n, nleB, nleE, efa1/lifA, pagC-like, nleH1-2, ureC, nleC, ecf4, paa, pic, nleG2-3, Z2099) using three multiplex PCRs. For all PCRs, DNA was extracted by boiling, primers were $5^{\prime}$ end labelled (6-FAM, VIC or PET), and PCRs were run and analysed as described previously (Supplemental Table 3) [19].

\section{Clustering and statistics}

We performed cluster analysis with the presence and absence of 33 virulence genes and subtypes of stx 1 and stx 2 in BioNumerics v.7.6 (Applied Maths, Belgium) using an unweighted pair group method with arithmetic mean (UPGMA) for phylogeny. Statistical analyses were performed in Stata version 13.1 (StataCorpLP, USA). Univariable analyses were performed by calculating odds ratios (ORs) by assigning the presence of virulence genes as cases and absence thereof as controls, and HUS as the outcome variable. Virulence genes were considered significantly associated with HUS if the $p$-value was $<0.05$. Significant factors were analysed in a multivariable logistic regression model adjusted for age group and Shiga toxin to calculate adjusted odds ratios (aORs) with $95 \%$ confidence intervals (CIs).

\section{Results}

\section{Description of cases}

The description of cases $(n=333)$ and characteristics of isolates $(n=334)$ from 1992 to 2012 have been published previously [5]. Briefly, the total number of cases was 339, with 190 females $(56 \%)$ and median age 14 years (range $<1$ to 97$)$. The age distribution displayed two peaks, at age groups $\leq 5$ years $(n=134,40 \%)$ and $21-40$ years $(n=67,20 \%)$. Half of the 
cases ( $n=171,50 \%$ ) were non-import cases, $146(43 \%)$ were hospitalised and $31(9 \%)$ were reported to have developed HUS.

\section{Serogroups and serotypes}

A total of 340 isolates were typed into 24 different $\mathrm{O}$ serogroups. The most frequent $\mathrm{O}$ serogroups included $\mathrm{O} 157$ $(n=115,34 \%), \mathrm{O} 103(n=50,15 \%), \mathrm{O} 26(n=34,10 \%)$ and O145 $(n=25,7 \%)$. The most frequent serotypes included O157: $\mathrm{H} / \mathrm{H}^{-}(n=115,34 \%), \mathrm{O} 103: \mathrm{H} 2(n=47,14 \%)$, O26:H11 $(n=34,10 \%)$ and O145:H28 $(n=18,5 \%)$. Ten of the $\mathrm{O} 157$ isolates $(9 \%)$ were sorbitol fermenters.

\section{Distribution of stx genes}

A total of 218 isolates (64\%) were positive for stx1 [stxla $(n=192)$, stxlc $(n=23)$, stxld $(n=3)], 212$ isolates $(62 \%)$ were positive for stx2 [stx2a $(n=90), \operatorname{stx} 2 b(n=32), s t x 2 c$ $(n=101), \operatorname{stx} 2 d(n=9), \operatorname{stx} 2 g(n=2)]$ and 91 isolates $(43 \%)$ were positive for both stx 1 and $s t x 2$.

\section{Distribution of toxins, adhesins and MRA}

On average, isolates were positive for 15 virulence genes (range: 1-24); two toxins (range: 0-4), five adhesins (range: 0-8) and eight MRA genes (range: 0-13). A total of 319 isolates $(94 \%)$ were identified with toxin genes other than stx 1 and/or stx2. The most common toxin genes identified were ehxA $(n=290)$, StcE/StcE ${ }_{0103}(n=194)$ and $s u b A$ $(n=42)$. A total of 338 isolates $(99 \%)$ were identified with adhesion genes, most commonly $\operatorname{IpfA}_{O 26}(n=306)$, eae $(n=252)$ and $i h a A(n=243)$. A total of $306(90 \%)$ of the isolates were identified with at least one MRA gene. The most common genes identified were nleB $(n=250)$, Z2099 $(n=248)$, nleE and ent/espL2n $(n=247)$ (Table 1$)$. eae-positive $(n=252)$ and eae-negative $(n=88)$

All eae-positive isolates were negative for aaiC and $e i b G$, in addition to the majority being negative for saa $(n=251)$, cnf $(n=251), \operatorname{subA}(n=250)$ and $\operatorname{ast} A(n=248)$. All eae-negative isolates were also negative for tox $B$ and nleH1-2, in addition to the majority being negative for $\operatorname{cnf}(n=87)$, nleC $(n=86)$, nle $G 2-3(n=86)$ and aaiC $(n=85)$. All HUS cases were positive for eae.

\section{O157:H7/H $(n=115)$}

On average, $\mathrm{O} 157: \mathrm{H} 7 / \mathrm{H}^{-}$isolates were positive for 21 virulence genes (range: 9-24); two toxins (range: 1-4), seven adhesins (range: 4-8) and 11 MRA (range: 0-13). All $\mathrm{O} 157: \mathrm{H} / \mathrm{H}^{-}$isolates were positive for eae, Ipf1 ${ }_{\text {O157/OI-141 }}$ and Ipf $2_{O 157 / O I-154}$. Conversely, none were positive for saa, aaiC, IpfA $A_{O 113}$, ehaA and $s u b A$. Major differences between non-sorbitol-fermenting O157 (NSFO157) and SFO157 were seen for $i h a A, \operatorname{esp} P$, tox $B$ and $u r e C$, which were absent from all SFO157 $(n=10)$ and present in almost all NSFO157 (ihaA, $n=105$; $\operatorname{esp} P, n=95$; tox $B, n=104$; ure $C, n=101)$. Conversely, $c d t B I-I V$ was present in the majority of SFO157 $(n=7,70 \%)$ and in a minority of NSFO157 $(n=8$, $8 \%)$. Among isolates from patients developing HUS of this serotype $(n=12)$, all isolates were positive for $I p f A_{O 26}$ and all were negative for $e i b G$, astA, cnf, fyuA and pic. Differences among the NSFO157 and SFO157 developing HUS were seen for $i h a A$, agn43 ${ }_{E D L 933}$, espP and toxB, which were present in all NSFO157 and absent from all SFO157.

\section{O103:H2 $(n=47)$}

On average, $\mathrm{O} 103: \mathrm{H} 2$ isolates were positive for 13 virulence genes (range: 11-17); two toxins (range: 1-3), three adhesins (range: 2-7) and eight MRA (range: 6-9). All O103:H2

Table 1 Virulence genes present and absent in isolates from the four most frequent Shiga toxin-producing Escherichia coli (STEC) serotypes and associated cases of haemolytic uraemic syndrome (HUS)

\begin{tabular}{|c|c|c|c|c|c|c|}
\hline Serotype & No. & Present in all & Absent from all & HUS $(n)$ & $\begin{array}{l}\text { Present in } \\
\text { all HUS }\end{array}$ & $\begin{array}{l}\text { Absent from } \\
\text { all HUS }\end{array}$ \\
\hline $\mathrm{O} 157: \mathrm{H}^{-}$ & 115 & $\begin{array}{l}\text { eae, Ipf1 } \\
\quad \text { Ipf } 2_{\text {O157/OI-151 }}, \\
\end{array}$ & saa, aaiC, IpfA $A_{O 113}$, ehaA, subA & 12 & $I p f A_{O 26}$ & $\begin{array}{l}\text { eibG, ast } A, \text { cnf, } \\
\quad f y u A, p i c\end{array}$ \\
\hline O103:H2 & 47 & $\begin{array}{l}\text { IpfA } \\
\text { O26, ehaA, efa1/lifA, } \\
\text { Z2099, nleE, nleB }\end{array}$ & $\begin{array}{l}\text { aaiC, toxB, IpfA } A_{O 113}, I p f 2_{\text {O157/OI-154, }} \\
\quad \text { eibG, cnf, cdtB I-IV, nleH1-2, fyuA, pic }\end{array}$ & 0 & & \\
\hline O26:H11 & 34 & $\begin{array}{l}\text { eae, iha1, IpfA } A_{O 113}, \text { IpfA } \\
\text { ehaA }, \text { efa1/lifA, ecf4, } \mathrm{Z} 2099, \\
\text { nleE, nleB, paa, fyuA, } \\
\text { ent/espL2n }\end{array}$ & $\begin{array}{l}\text { saa, Ipf1 } 1_{O 157 / O I-141}, \operatorname{Ipf} 2_{\text {OI57/OI-154, }} \\
\quad \text { eibG, toxB, astA, chf, cdtB I-IV, } \\
\quad \text { subA, nleC, pic }\end{array}$ & 4 & $\begin{array}{l}\text { agn } 43_{E D L 933}, \text { ureC }, \\
\quad \text { nleH1-2, nleG2-3 }\end{array}$ & pagC-like \\
\hline O145:H28 & 18 & $\begin{array}{l}\text { iha1, agn } 43_{E D L 933}, \text { Ipf1 } \\
\text { IpfA } A_{O 26}, \text { ehxA, efa1/lifA, Z2091, } \\
\text { nleB, nleE, paa, ureC, } \\
\text { ent/espL2n }\end{array}$ & $\begin{array}{l}\text { saa, aaiC, toxB, Ipf } A_{O 113}, \text { ehaA, } \\
\text { Ipf } 2_{\text {OI57/OI-154, eibG, astA, cnf, }} \\
\text { cdtB I-IV, subA, } \\
\text { nleH1-2, fyuA, nleG2-3 }\end{array}$ & 1 & $\begin{array}{l}\text { eae, espP, ecf4, } \\
\quad \text { Z2009 }\end{array}$ & $\begin{array}{l}\text { pagC-like, } \\
\text { nleC, pic }\end{array}$ \\
\hline
\end{tabular}


isolates were positive for IpfA $A_{O 26}$, ehaA, efa1/lifA, Z2099, $n l e E$ and $n l e B$. Conversely, none of the isolates were positive for aaiC, toxB, IpfA ${ }_{0113}, I_{p f} 2_{\text {O157/OI-154, }}$ eibG, cnf, cdtB I-IV, nleH1-2, fyuA and pic. All STEC O103:H2 carried stxla and none of these isolates were from cases that developed HUS.

O26:H11 $(n=34)$

On average, $\mathrm{O} 26: \mathrm{H} 11$ isolates were positive for 19 virulence genes (range: 16-20); one toxin (range: 1-2), seven adhesins (range: 6-7) and 11 MRA (range: 9-12). All O26:H11 isolates were positive for eae, iha1, IpfA ${ }_{O 113}$, IpfA $A_{O 26}$, ehaA, efa1/lifA, ecf4, Z2099, nleE, nleB, paa, fyuA and ent/espL2n, and all

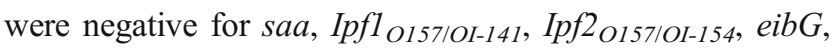
toxB, ast A, cnf, cdtB I-IV, subA, nleC and pic. Among isolates from patients developing HUS of this serotype $(n=4)$, all isolates were positive for agn $43_{E D L 933}$, ureC, nleH1-2 and nleG2-3, and all were negative for pagC-like.

\section{O145:H28 $(n=18)$ and O145:H? $(n=7)$}

On average, $\mathrm{O} 145: \mathrm{H} 28$ isolates were positive for 15 virulence genes (range: 14-16); two toxins (range: 1-2), five adhesins (range: 4-6) and eight MRA (range: 7-9). All O145:H28 isolates were positive for ihal, agn $43_{E D L 933}$, Ipf1 $1_{\text {O157/OI-141, }}$, IpfA ${ }_{O 26}$, ehxA, efal/lifA, Z2099, nleB, nleE, paa, ureC and entlespL2n, and all were negative for saa, aaiC, tox $B$,

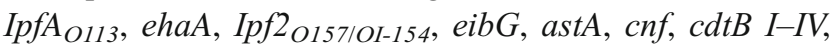
subA, nleH1-2, fyuA and nleG2-3. One of the O145:H28 isolates was recovered from a case that developed HUS and five $\mathrm{O} 145: \mathrm{H}$ ? isolates were recovered from cases that developed HUS. All HUS isolates were positive for stx $2 a$, IpfA $A_{O 113}$ and nleH1-2, whereas all non-HUS isolates were negative. Conversely, all isolates from HUS cases were negative for iha 1, agn $43_{E D L 933}$, Ipf1 $1_{O 157 / O 1-141}$ and StcE/StcE $E_{O 103}$, whereas all non-HUS isolates were positive.

\section{Clusters and statistical associations}

Analysis based on an UPGMA phylogeny dispersed the isolates into diverse virulence gene combinations (Fig. 1). Phylogenetic clusters of related isolates were seen within the dominant serotypes, O157:H7/ $\mathrm{H}^{-}, \mathrm{O} 103: \mathrm{H} 2, \mathrm{O} 26: \mathrm{H} 11$ and O145:H28. Isolates from cases developing HUS were seen distributed between multiple clusters, with certain clusters appearing to be less commonly associated with HUS than others. All isolates from HUS cases $(n=32)$ were positive for eae and IpfA $A_{O 26}$, and none were positive for $s a a, e i b G$, astA, cnf, subA and pic. None of the isolates recovered from cases aged between 20 and 60 years $(n=117)$, were serotyped as O103: $\mathrm{H} 2(n=47)$, positive for $\operatorname{stx} 2 b(n=32), \operatorname{stx} 2 d(n=3)$, stx $2 g(n=2), \operatorname{stx} 1 c(n=23)$ or stxld $(n=3)$, or recovered from cases that developed HUS. Univariable analyses identified 11 virulence genes with a significant association with the development of HUS in addition to age $\leq 5$ years and st $x 2 a$ (Table 2). Multivariable analyses independent of serotype, when adjusted for age group and presence of Stx, confirmed age $\leq 5$ years (aOR $12.7,95 \%$ CI; 4.2-39), stx $2 a$ (aOR 28.6, 95\% CI; 12.7-158) and the virulence gene nleHI-2 (aOR 8.4, 95\% CI; 2.18-32.3) as independent risk factors for the development of HUS (Table 2).

\section{Discussion}

Age ( $\leq 5$ years) and the presence of an stx $2 a$ - and eae-positive STEC have previously been identified as risk factors for the development of HUS in several studies [4, 20-25]. In Norway, these associations were confirmed in a recent study which estimated the odds of developing HUS to be 16 times greater for children aged 5 years or less (OR 16.7) and 30 times greater for infections with stx2a-producing STEC (OR 30.1) [5]. In the present study, we investigated the presence of 31 different virulence genes; five toxin genes, 12 adhesion genes and 14 MRA-associated genes, in addition to eae, ehxA and subtypes of stx 1 and stx2, and their association with HUS development.

Our results showed that the distribution and combination of virulence genes were clustered within distinct serotypes, with cases of HUS dispersed among the different virulent gene clusters. The largest accumulation and combination of virulence genes was seen among isolates of serotype $\mathrm{O} 157: \mathrm{H}^{-} / \mathrm{H} 7$. The combination of virulence genes differed between NSFO157 and SFO157. We observed, as demonstrated in previous studies, that the mosaic structure of OI-43 in SFO157 isolates lacked the ihal and $u r e C$ genes [26]. Also, as seen in earlier studies, the plasmid pO157-associated genes espA and toxB were absent from our SFO157 isolates [27]. The NSFO157 isolates were mostly negative for cytolethal distending toxin gene $c d t(8 \%)$ compared to SFO157 isolates, which were typically positive (70\%). An association of $c d t$ and HUS among eae-negative non-SFO157 has previously been suggested, although the association between $c d t$ and HUS in SFO157 is still unclear [28, 29]. Our results showed that $67 \%$ of SFO157 isolates associated with HUS were $c d t$-positive. Also, however, SFO157 isolates not associated with HUS were positive for $c d t$ (75\%). In addition to sorbitol fermentation, the presence of stx $2 a$ was the marker with the highest positive predictive value (PPV) for O157 association with HUS (29\%). A single NSFO157 isolate carried only an stx2c subtype of Stx and was associated with HUS. This isolate displayed a very different virulence gene profile to the other NSFO157 isolates, and was the only isolate negative for 


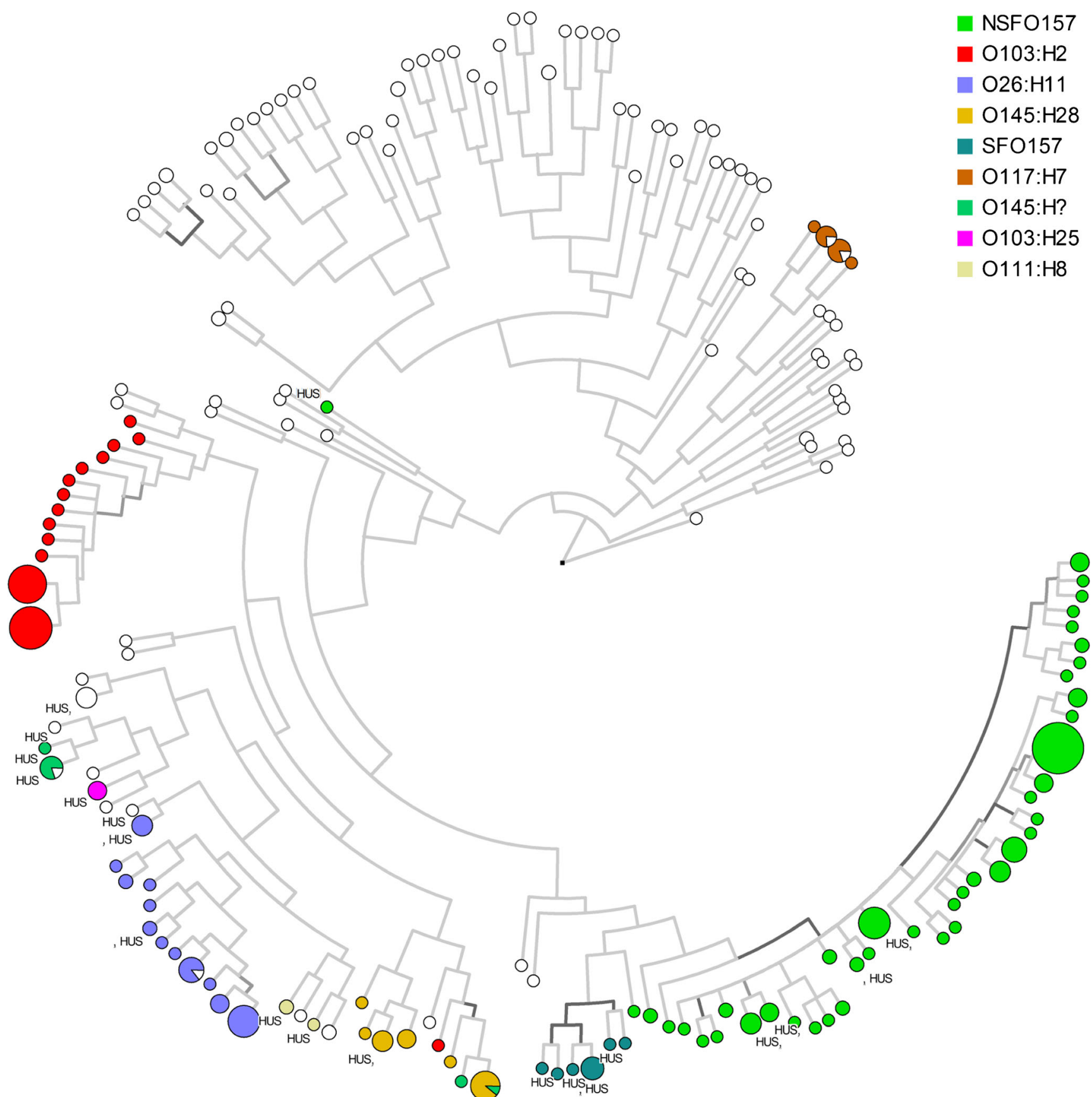

Fig. 1 Unweighted pair group method with arithmetic mean (UPGMA) phylogenetic estimation of the relatedness of Shiga toxin-producing Escherichia coli (STEC) isolates $(n=340)$ based on the absence or presence of 33 virulence genes and subtypes of stx 1 and stx 2 . Phylogeny constructed using the majority summary method with 200 sample permutations. Branch intensity is according to descending

nleC, ent/espL2n, pagC-like, nleG2-3, nleH1-2, ureC, paa, nleB, ec4, efal/lifA and StcE/StcE $E_{\mathrm{Ol03}}$ (Fig. 1). Its virulence gene combination suggested a low virulent strain and it was supposed that unknown host factors may have played an important role in the development of HUS in this case. This was supported by the fact that this STEC was isolated from a 66-year old-patient, who resampling support (light-dark). Global cophenetic correlation was estimated to be $94 \%$. Each node represents a unique combination of virulence genes, with the size of the node correlating to the number of isolates with that combination. Major serotypes are coloured according to the legend. Isolates from cases developing haemolytic uraemic syndrome (HUS) are indicated on the figure

was the only HUS patient above 12 years of age in the study population.

The least number and combination of virulence genes among the most frequent serotypes were observed for O103:H2 isolates. Most O103:H2 isolates were grouped within two major virulence gene clusters, separated only by the presence and absence of agn $43_{E D L 933}$ and nleG2-3. nleG2-3 is encoded on 
Table 2 Factors in STEC isolates with a significant $(p<0.05)$ association to the development of HUS $(n=32)$ among STEC infections in Norway 1992-2013 $(n=340)$

\begin{tabular}{|c|c|c|c|c|c|c|c|c|}
\hline \multirow[t]{2}{*}{ Factor } & \multicolumn{2}{|c|}{ Cases exposed } & \multicolumn{2}{|c|}{ Controls exposed } & \multirow[t]{2}{*}{$\mathrm{OR}^{\mathrm{a}}$} & \multirow[t]{2}{*}{$p$-Value } & \multirow[t]{2}{*}{$\mathrm{aOR}$} & \multirow[t]{2}{*}{$95 \% \mathrm{CI}^{\mathrm{b}}$} \\
\hline & $n$ & $\%$ & $n$ & $\%$ & & & & \\
\hline stx $2 a$ & 29 & 90.6 & 61 & 19.8 & 39.1 & $<0.001$ & 28.6 & $7.83-104$ \\
\hline age $\leq 5$ years $^{\mathrm{c}}$ & 27 & 84.4 & 108 & 35.1 & 10.0 & $<0.001$ & 12.7 & $4.16-39.0$ \\
\hline efa1/lifA & 31 & 96.9 & 211 & 68.5 & 14.3 & $<0.01$ & & \\
\hline paa & 31 & 96.9 & 211 & 68.5 & 14.3 & $<0.01$ & & \\
\hline ecf4 & 31 & 96.9 & 215 & 69.9 & 13.4 & $<0.01$ & & \\
\hline nleE & 31 & 96.9 & 216 & 70.1 & 13.2 & $<0.01$ & & \\
\hline ent/espL2n & 31 & 96.9 & 216 & 70.1 & 13.2 & $<0.01$ & & \\
\hline nleB & 31 & 96.9 & 219 & 71.1 & 12.6 & $<0.01$ & & \\
\hline nleH1-2 & 29 & 90.6 & 135 & 43.8 & 12.4 & $<0.001$ & 8.40 & $2.18-32.3$ \\
\hline pagC-like & 26 & 81.3 & 152 & 49.4 & 4.45 & $<0.01$ & & \\
\hline Z2099 & 29 & 90.6 & 219 & 71.1 & 3.39 & $<0.05$ & & \\
\hline nleG2-3 & 24 & 75.0 & 152 & 49.4 & 3.08 & $<0.01$ & & \\
\hline $\operatorname{lpf} A_{\mathrm{O} 113}$ & 19 & 59.4 & 103 & 33.4 & 2.91 & $<0.01$ & & \\
\hline
\end{tabular}

the pathogenicity island OI-57, which also encodes Z2099. As previously shown, all O103:H2 isolates were positive for Z2099 [30], but only one of the two clusters was positive for nleG2-3. Although the function of OI-57 is not entirely clear, OI-57 has previously been demonstrated to be significantly associated with human pathogenic STEC $[8,30,31]$. All O103:H25 isolates in our collection were associated with HUS and positive for stx 2a, IpfA $\mathrm{Olli}_{13}$ and nleH1-2, whereas all O103:H2 isolates were negative for these virulence factors. Furthermore, only two of the $\mathrm{O} 103: \mathrm{H} 2$ isolates but all of the $\mathrm{O} 103: \mathrm{H} 25$ isolates $(n=3)$ were positive for ureC and pagC-like [32].

Among the virulence genes screened, five were encoded on the pathogenicity island OI-122 (efa1/lifA, entlespL2n, nleB, nleE, pagC-like). A complete OI-122 was seen in $98 \%$ of the O157 isolates, with only two isolates negative for efal/lifA. Among the O103:H2 isolates, OI-122 genes efal/lifA, ent/ espL2n, nle and nleE were seen to be co-located in $98 \%$ of the isolates, with $p a g C$-like being only present in two isolates. An absent or truncated pagC may be an indicator for low virulence, as shown earlier [33]. The absence of pagC-like is also evident in $\mathrm{O} 26: \mathrm{H} 11$ isolates, all of which were positive for all other OI-122-associated genes. However, contrary to $\mathrm{O} 103$ isolates, all $\mathrm{O} 26: \mathrm{H} 11$ isolates that were associated with HUS were negative for pagC-like. In O26:H11 isolates, as seen for $\mathrm{O} 157$ isolates, stx $2 a$ was the marker with the highest PPV for association with HUS (44\%). Isolates of the O145 serogroup with an $\mathrm{H}$ ? phenotype were more frequently associated with HUS than $\mathrm{H} 28$ ( $71 \%$ vs. 5\%). Overall, our results indicated that the virulence gene composition varies within each serotype, along with the combination of virulence genes required for an HUSassociated subtype (Supplemental Fig. 2).
In our univariable analysis, all of the OI-57 and OI-122 genes together with $c d t$, IpfA $A_{113}$ and $u r e C$, the plasmidencoded ecf4 (pO157) and the pathogenicity island OI-71 located in nleH1-2 were seen to be significantly associated with the development of HUS. However, in a multivariable logistic regression model adjusted for age and stx $2 a$, only nleH1-2 remained with a significant independent association with HUS (aOR 8.4). nleH1-2 has previously been described as an immune system modulator, functioning through inhibition of the NF-KB activation [34, 35]. Studies have proposed that it likely exhibits a role in the colonisation process rather than the attachment and effacement phase of an STEC infection [36]. Its location on OI-71 has been suggested to be an important discriminator, along with OI-122 for highly virulent enteropathogenic Escherichia coli (EPEC) and STEC strains [8, 13, 18, 37].

The sensitivity of nleH1-2 in the detection of STEC isolates recovered from HUS patients was estimated to be $91 \%$, which implied that only three isolates recovered from HUS patients were negative for $n l e H 1-2$. Included in these isolates was the stx $2 c$-only NSFO157 isolate from a 66-year-old patient and an O111 isolate recovered from an HUS patient with multi-strain infection where one strain was nleH1-2-positive (carrying stxla and stx2a) and the other strain was negative (stxla only). Excluding these two isolates as probable non-HUS-associated, the sensitivity of nleH1-2 increased to $97 \%$, matching the sensitivity of stx $2 a$, although with a lower specificity ( $56 \%$ vs. $80 \%$ ). The negative predictive value (NPV), when combining age ( $\leq 5$ years), eae, stx $2 a$ and nleH1-2, was estimated to be $97 \%$, indicating that the likelihood of developing HUS was very low if all these factors were negative. The PPV was estimated to be $73 \%$, which was an increase from $68 \%$ if we only considered 
age ( $\leq 5$ years), eae and $s t x 2 a$. Also, the specificity increased from 96 to $97 \%$ when including nleH1-2, allowing for a more accurate exclusion of non-HUS-associated STEC. The matter of concern was the low sensitivity (75\%), which implied that $25 \%$ of the STEC isolated from HUS patients in the current study did not harbour this combination of risk factors. However, when excluding the two probable non-HUS-associated isolates, the sensitivity increased to $80 \%$. Overall, the inclusion of nleH1-2 increased our probability of discerning HUS-associated STEC, although other virulence factors and host-specific factors are important when assessing patients at risk of developing HUS.

Our study was limited by the virulence genes selected and the number of isolates tested. A methodological selection bias was present for O157 due to diagnostic challenges and, consequently, underreporting of non-O157 STEC. The low number of isolates and HUS cases prevented a serotype-specific statistical HUS association analysis. Furthermore, we only included STEC isolates in our study, and the prevalence of these virulence genes in other EPEC were not determined and, therefore, a direct association to the development of HUS is likely an overestimation. Also, we did not perform any gene expression analysis to confirm the level of gene translation. Lastly, data on host factors other than age were not available to allow for adjustment in our statistical model.

Our results showed that the non-LEE-encoded immune system modulator nleH1-2, together with age $\leq 5$ years and stx $2 a$, may contribute significantly in discerning HUS-associated STEC (PPV 73\%). The OR of developing HUS from an STEC infection was eight times higher when stains were positive for nleH1-2. Larger studies are required to increase the statistical power of the reported significant associations to enable a better identification of HUS-associated STEC and review infection control guidelines in light of new knowledge. We recommend the Norwegian NRL to include screening for nleH1-2 in routine STEC surveillance to improve the supervision of appropriate infection control measures for sporadic cases and during STEC outbreaks.

Acknowledgements We would like to thank all the technical staff at the Department of Molecular Biology and at the Department of Bacteriology at the Norwegian Institute of Public Health (NIPH) and all medical microbiological laboratories in Norway for collecting and sending isolates to the NIPH.

\section{Compliance with ethical standards}

Funding This study was funded by the Norwegian Institute of Public Health.

Conflict of interest The authors declare that they have no conflict of interest.

Ethical approval For this type of study, formal consent is not required.

Informed consent No identifying information is included
Open Access This article is distributed under the terms of the Creative Commons Attribution 4.0 International License (http:// creativecommons.org/licenses/by/4.0/), which permits unrestricted use, distribution, and reproduction in any medium, provided you give appropriate credit to the original author(s) and the source, provide a link to the Creative Commons license, and indicate if changes were made.

\section{References}

1. Smith JL, Fratamico PM, Gunther NW 4th (2014) Shiga toxinproducing Escherichia coli. Adv Appl Microbiol 86:145-197. doi:10.1016/B978-0-12-800262-9.00003-2

2. Bryan A, Youngster I, McAdam AJ (2015) Shiga toxin producing Escherichia coli. Clin Lab Med 35(2):247-272. doi:10.1016/j.cll. 2015.02.004

3. Boyce TG, Swerdlow DL, Griffin PM (1995) Escherichia coli O157:H7 and the hemolytic-uremic syndrome. N Engl J Med 333(6):364-368. doi:10.1056/NEJM199508103330608

4. Persson S, Olsen KEP, Ethelberg S, Scheutz F (2007) Subtyping method for Escherichia coli shiga toxin (verocytotoxin) 2 variants and correlations to clinical manifestations. J Clin Microbiol 45(6): 2020-2024

5. Brandal LT, Wester AL, Lange H, Løbersli I, Lindstedt BA, Vold L, Kapperud G (2015) Shiga toxin-producing Escherichia coli infections in Norway, 1992-2012: characterization of isolates and identification of risk factors for haemolytic uremic syndrome. BMC Infect Dis 15:324. doi:10.1186/s12879-015-1017-6

6. Boerlin P, McEwen SA, Boerlin-Petzold F, Wilson JB, Johnson RP, Gyles CL (1999) Associations between virulence factors of Shiga toxin-producing Escherichia coli and disease in humans. J Clin Microbiol 37(3):497-503

7. Welinder-Olsson C, Kaijser B (2005) Enterohemorrhagic Escherichia coli (EHEC). Scand J Infect Dis 37(6-7):405-416. doi:10.1080/00365540510038523

8. Bugarel M, Martin A, Fach P, Beutin L (2011) Virulence gene profiling of enterohemorrhagic (EHEC) and enteropathogenic (EPEC) Escherichia coli strains: a basis for molecular risk assessment of typical and atypical EPEC strains. BMC Microbiol 11:142. doi:10.1186/1471-2180-11-142

9. McDaniel TK, Jarvis KG, Donnenberg MS, Kaper JB (1995) A genetic locus of enterocyte effacement conserved among diverse enterobacterial pathogens. Proc Natl Acad Sci U S A 92(5):16641668

10. Nguyen Y, Sperandio V (2012) Enterohemorrhagic E. coli (EHEC) pathogenesis. Front Cell Infect Microbiol 2:90. doi:10.3389/fcimb. 2012.00090

11. Wick LM, Qi W, Lacher DW, Whittam TS (2005) Evolution of genomic content in the stepwise emergence of Escherichia coli O157:H7. J Bacteriol 187(5):1783-1791. doi:10.1128/JB.187.5. 1783-1791.2005

12. Karmali MA, Mascarenhas M, Shen S, Ziebell K, Johnson S, ReidSmith R, Isaac-Renton J, Clark C, Rahn K, Kaper JB (2003) Association of genomic O island 122 of Escherichia coli EDL 933 with verocytotoxin-producing Escherichia coli seropathotypes that are linked to epidemic and/or serious disease. J Clin Microbiol 41(11):4930-4940

13. Coombes BK, Wickham ME, Mascarenhas M, Gruenheid S, Finlay BB, Karmali MA (2008) Molecular analysis as an aid to assess the public health risk of non-O157 Shiga toxin-producing Escherichia coli strains. Appl Environ Microbiol 74(7):2153-2160. doi:10. 1128/AEM.02566-07 
14. McWilliams BD, Torres AG (2014) Enterohemorrhagic Escherichia coli adhesins. Microbiol Spectr 2(3). doi:10.1128/ microbiolspec.EHEC-0003-2013

15. Stevens MP, Frankel GM (2014) The locus of enterocyte effacement and associated virulence factors of enterohemorrhagic Escherichia coli. Microbiol Spectr 2(4):EHEC-0007-2013. doi:10. 1128/microbiolspec.EHEC-0007-2013

16. Brandt SM, King N, Cornelius AJ, Premaratne A, Besser TE, On SL (2011) Molecular risk assessment and epidemiological typing of Shiga toxin-producing Escherichia coli by using a novel PCR binary typing system. Appl Environ Microbiol 77(7):2458-2470. doi: 10.1128/AEM.02322-10

17. Andersson T, Nilsson C, Kjellin E, Toljander J, Welinder-Olsson C, Lindmark H (2011) Modeling gene associations for virulence classification of verocytotoxin-producing $E$. coli (VTEC) from patients and beef. Virulence 2(1):41-53

18. Bugarel M, Beutin L, Fach P (2010) Low-density macroarray targeting non-locus of enterocyte effacement effectors (nle genes) and major virulence factors of Shiga toxin-producing Escherichia coli (STEC): a new approach for molecular risk assessment of STEC isolates. Appl Environ Microbiol 76(1):203-211. doi:10. 1128/AEM.01921-09

19. Brandal LT, Lindstedt BA, Aas L, Stavnes TL, Lassen J, Kapperud G (2007) Octaplex PCR and fluorescence-based capillary electrophoresis for identification of human diarrheagenic Escherichia coli and Shigella spp. J Microbiol Methods 68(2):331-341. doi:10. 1016/j.mimet.2006.09.013

20. Ethelberg S, Olsen KEP, Scheutz F, Jensen C, Schiellerup P, Enberg J, Petersen AM, Olesen B, Gerner-Smidt P, Mølbak K (2004) Virulence factors for hemolytic uremic syndrome, Denmark. Emerg Infect Dis 10(5):842-847

21. Mellmann A, Bielaszewska M, Köck R, Friedrich AW, Fruth A, Middendorf B, Harmsen D, Schmidt MA, Karch H (2008) Analysis of collection of hemolytic uremic syndrome-associated enterohemorrhagic Escherichia coli. Emerg Infect Dis 14(8): $1287-1290$

22. Friedrich AW, Bielaszewska M, Zhang W-L, Pulz M, Kuczius T, Ammon A, Karch H (2002) Escherichia coli harboring Shiga toxin 2 gene variants: frequency and association with clinical symptoms. $\mathrm{J}$ infect Dis 185(1):74-84

23. Gould LH, Mody RK, Ong KL, Clogher P, Cronquist AB, Garman KN, Lathrop S, Medus C, Spina NL, Webb TH, White PL, Wymore K, Gierke RE, Mahon BE, Griffin PM; Emerging Infections Program Foodnet Working Group (2013) Increased recognition of non-O157 Shiga toxin-producing Escherichia coli infections in the United States during 2000-2010: epidemiologic features and comparison with E. coli O157 infections. Foodborne Pathog Dis 10(5): 453-460

24. Beutin L, Krause G, Zimmermann S, Kaulfuss S, Gleier K (2004) Characterization of Shiga toxin-producing Escherichia coli strains isolated from human patients in Germany over a 3-year period. J Clin Microbiol 42(3): 1099-1108

25. Byrne L, Vanstone GL, Perry NT, Launders N, Adak GK, Godbole G, Grant KA, Smith R, Jenkins C (2014) Epidemiology and microbiology of Shiga toxin-producing Escherichia coli other than serogroup O157 in England, 2009-2013. J Med Microbiol 63(Pt 9):1181-1188

26. Janka A, Becker G, Sonntag AK, Bielaszewska M, Dobrindt U, Karch H (2005) Presence and characterization of a mosaic genomic island which distinguishes sorbitol-fermenting enterohemorrhagic Escherichia coli $\mathrm{O} 157: \mathrm{H}-$ from E. coli O157:H7. Appl Environ Microbiol 71(8):4875-4878. doi:10.1128/AEM.71.8.4875-4878. 2005

27. Bettelheim KA, Whipp M, Djordjevic SP, Ramachandran V (2002) First isolation outside Europe of sorbitol-fermenting verocytotoxigenic Escherichia coli (VTEC) belonging to O group O157. J Med Microbiol 51(8):713-714. doi:10.1099/0022-131751-8-713

28. Bielaszewska M, Fell M, Greune L, Prager R, Fruth A, Tschäpe H, Schmidt MA, Karch H (2004) Characterization of cytolethal distending toxin genes and expression in Shiga toxin-producing Escherichia coli strains of non-O157 serogroups. Infect Immun 72(3):1812-1816

29. Friedrich AW, Lu S, Bielaszewska M, Prager R, Bruns P, Xu JG, Tschäpe H, Karch H (2006) Cytolethal distending toxin in Escherichia coli O157:H7: spectrum of conservation, structure, and endothelial toxicity. J Clin Microbiol 44(5):1844-1846. doi: 10.1128/JCM.44.5.1844-1846.2006

30. Delannoy S, Beutin L, Fach P (2013) Discrimination of enterohemorrhagic Escherichia coli (EHEC) from non-EHEC strains based on detection of various combinations of type III effector genes. J Clin Microbiol 51(10):3257-3262. doi:10.1128/ JCM.01471-13

31. Imamovic L, Tozzoli R, Michelacci V, Minelli F, Marziano ML, Caprioli A, Morabito S (2010) OI-57, a genomic island of Escherichia coli O157, is present in other seropathotypes of Shiga toxin-producing $E$. coli associated with severe human disease. Infect Immun 78(11):4697-4704. doi:10.1128/IAI.00512-10

32. Ju W, Shen J, Toro M, Zhao S, Meng J (2013) Distribution of pathogenicity islands OI-122, OI-43/48, and OI-57 and a highpathogenicity island in Shiga toxin-producing Escherichia coli. Appl Environ Microbiol 79(11):3406-3412. doi:10.1128/AEM. 03661-12

33. Konczy P, Ziebell K, Mascarenhas M, Choi A, Michaud C, Kropinski AM, Whittam TS, Wickham M, Finlay B, Karmali MA (2008) Genomic O island 122, locus for enterocyte effacement, and the evolution of virulent verocytotoxin-producing Escherichia coli. J Bacteriol 190(17):5832-5840. doi:10.1128/JB.00480-08

34. Hemrajani C, Marches O, Wiles S, Girard F, Dennis A, Dziva F, Best A, Phillips AD, Berger CN, Mousnier A, Crepin VF, Kruidenier L, Woodward MJ, Stevens MP, La Ragione RM, MacDonald TT, Frankel G (2008) Role of NleH, a type III secreted effector from attaching and effacing pathogens, in colonization of the bovine, ovine, and murine gut. Infect Immun 76(11):4804 4813. doi:10.1128/IAI.00742-08

35. Dean P, Kenny B (2009) The effector repertoire of enteropathogenic E. coli: ganging up on the host cell. Curr Opin Microbiol 12(1): 101-109. doi:10.1016/j.mib.2008.11.006

36. Holmes A, Lindestam Arlehamn CS, Wang D, Mitchell TJ, Evans TJ, Roe AJ (2012) Expression and regulation of the Escherichia coli $\mathrm{O} 157: \mathrm{H} 7$ effector proteins $\mathrm{NleH} 1$ and NleH2. PLoS One 7(3): e33408. doi:10.1371/journal.pone.0033408

37. Haugum K, Brandal LT, Lindstedt BA, Wester AL, Bergh K, Afset JE (2014) PCR-based detection and molecular characterization of shiga toxin-producing Escherichia coli strains in a routine microbiology laboratory over 16 years. J Clin Microbiol 52(9):3156-3163. doi:10.1128/JCM.00453-14 